\title{
Physico-chemical and structural properties of the surfaces of Peptostreptococcus micros and Streptococcus mitis as compared to those of mutans streptococci, Streptococcus sanguis and Streptococcus salivarius
}

\author{
M. M. Cowan, ${ }^{1}$ H. C. VAN Der Mei, ${ }^{1}$ P. G. RouXheT ${ }^{2}$ and H. J. BusSCHER ${ }^{* 1}$ \\ ${ }^{1}$ Laboratory for Materia Technica, University of Groningen, Antonius Deusinglaan 1, 9713 AV Groningen, \\ The Netherlands \\ ${ }^{2}$ Université Catholique de Louvain, Unité de Chimie des Interfaces, Place Croix du Sud 2, B-1348 Louvain-la-Neuve, \\ Belgium
}

(Received 16 April 1992; revised 31 July 1992; accepted 13 August 1992)

\begin{abstract}
The surface properties of nine Streptococcus mitis and four Peptostreptococcus micros strains from the oral cavity were examined and compared with a large group of oral streptococci. Zeta potential and contact angle measurements were employed to determine physico-chemical cell surface properties. In addition, elemental surface concentration ratios were obtained via $\mathrm{X}$-ray photoelectron spectroscopy, and surface structures were examined with transmission electron microscopy. The $S$. mitis and $P$. micros strains were found to have higher isoelectric points, higher hydrophobicities and higher $\mathrm{N} / \mathrm{C}$ surface concentration ratios than some other oral streptococci. The combined data suggest that both species possess large amounts of surface protein. All the $S$. mitis strains displayed abundant surface fibrils in negative staining, but the $P$. micros strains were devoid of surface appendages indicating that surface protein is present in different forms in the two species. The surfaces of $S$. mitis and $P$. micros type strains differed significantly from the other strains examined.
\end{abstract}

\section{Introduction}

Streptococcus mitis and Peptostreptococcus micros are prevalent organisms in the oral cavity. S. mitis is one of the most frequently isolated bacteria in dental plaque, and also colonizes mucous membranes, most notably the cheek and tongue (Marsh \& Martin, 1980). Although it may cause dental caries, in most cases it is considered to be an innocuous member of the oral microflora (Hardie \& Marsh, 1978). Conversely, Peptostreptococcus is an anaerobic coccus found in substantial numbers in many forms of anaerobic mixed infections (Rogosa, 1971; Bourgault et al., 1980) and though it is detectable in healthy mouths (Socransky, 1970; Slots, 1979) its numbers increase dramatically in the presence of periodontal disease (Moore et al., 1982; Slots, 1979; Ter Steeg et al., 1987). Peptostreptococcus strains resemble Streptococcus strains in that they are Gram-positive cocci with a tendency to grow in chains, yet are distinguished by their requirement for strictly anaerobic conditions (Hofstad, 1985). While $S$. mitis colonizes supragingival

\footnotetext{
* Author for correspondence. Tel. 3150633140 ; fax 3150633159.
}

regions of the tooth, $P$. micros is found primarily below the gingival margin where anaerobic conditions prevail and is characterized by the production of various tissuedamaging enzymes, such as hyaluronidase and peptidase (Tam et al., 1987).

Successful colonization of most tissues requires adhesion of bacteria. The adhesion of a bacterium to a substratum is in turn influenced by the physico-chemical properties of its surface. In particular, the approach of a bacterium to a substratum surface is usually assumed to be mediated by electrostatic and Lifshitz-Van der Waals forces (Busscher \& Weerkamp, 1987). Upon close approach, stereochemical groups on the interacting surfaces may be brought close together through the above mentioned forces yielding a so-called "specific bond". Zeta potentials and hydrophobicity (assessed for instance by contact angle measurements) are the physico-chemical corollaries of the capacity of a surface to express these forces.

There are many examples of the use of zeta potential measurements to probe bacterial surfaces (Olsson et al., 1976; Van Loosdrecht et al., 1987; Mozes et al., 1989; Van der Mei et al., 1989a). In one study (Van der Mei et 
al., 1988a) the isoelectric point (IEP) of a Streptococcus salivarius fibrillated strain was much higher than the IEP found for a series of non-fibrillar mutants. Other work attests to the usefulness of contact angle studies (Van der Mei et al., 1989a; Silva-Filho et al., 1990) and X-ray photoelectron spectroscopy (XPS) (Millard et al., 1976; Amory et al., 1988; Van der Mei et al., 1991; Busscher et al., 1991) in determining microbial surface characteristics.

The aim of this study was to characterize the cell surface properties of $P$. micros and $S$. mitis by examining the hydrophobicity and surface charge characteristics of several strains of each species through the use of contact angle and zeta potential measurements, respectively. In addition, XPS has been performed to probe the elemental surface composition, and electron microscopy used to assess surface morphology of these bacteria. Results are compared with data obtained for a collection of oral streptococcal strains.

\section{Methods}

Bacterial strains and growth conditions. Bacteria used in this study are listed in Table 1 along with their sources. $P$. micres strains were grown in $0.06 \%$ peptone, $0.2 \%$ yeast extract, $2.5 \%(\mathrm{v} / \mathrm{v})$ horse serum. $S$. mitis strains were grown in Todd Hewitt Broth. $P$. micros strains were grown in an anaerobic cabinet under $10 \% \mathrm{H}_{2}, 85 \% \mathrm{~N}_{2}, 5 \% \mathrm{CO}_{2}$ (by vol.). $S$. mitis strains were cultured aerobically. Growth temperature was $37^{\circ} \mathrm{C}$ for all strains. Cultures were grown to stationary phase and harvested by centrifugation at $5000 \mathrm{~g}$. Cultures for use in zeta potential measurements were then washed twice and resuspended in potassium phosphate buffer ( $10 \mathrm{mM}, \mathrm{pH} 7 \cdot 0)$. For XPS, contact angle measurements and electron microscopy, cultures were washed twice in demineralized water.

Zeta potential measurements. Bacterial suspensions $\left(1 \times 10^{6}\right.$ cells. $\mathrm{ml}^{-1}$ ) were prepared in potassium phosphate buffer ( $\left.10 \mathrm{mM}\right)$, the $\mathrm{pH}$ of which had been adjusted to $2,3,4,5,7$ or 9 by the addition of $\mathrm{HCl}$ or $\mathrm{KOH}$. Addition of cells did not affect pH. A Lazer Zee Meter 501 (PenKem, Bedford Hills, NY) set at $150 \mathrm{~V}$ was used to determine the electrophoretic mobility of the cells which was then converted to apparent zeta potentials via the Smoluchowski equation (Abramson $e t$ al., 1942).

Contact angle measurements. The method for measuring contact angles on bacterial layers has been described (Busscher et al., 1984). Briefly, bacteria suspended in water were deposited on membrane filters to a thickness of 50-100 cells. After a standard drying time of $30 \mathrm{~min}$ advancing-type contact angles were measured using the sessile drop technique with the following liquids: water, $\alpha$-bromonaphthalene, formamide and diiodomethane. Water and formamide are used to probe polar hydrogen-donating and -accepting groups while $\alpha$ bromonaphthalene and diiodomethane probe apolar groups on the cell surface.

$X$-ray photoelectron spectroscopy (XPS). Bacterial pellets were quickly frozen in stainless steel cups by immersion in liquid nitrogen and lyophilized at $-10^{\circ} \mathrm{C}$ in a Lyovac GT1 lyophilizer (Leybold Heraeus, Cologne). The freeze dryer contained a liquid nitrogen cooled plate positioned next to the bacterial sample which prevented carbonaceous contamination during freeze drying. A magnesium anode was used for
Table 1. Bacterial strains used in this study

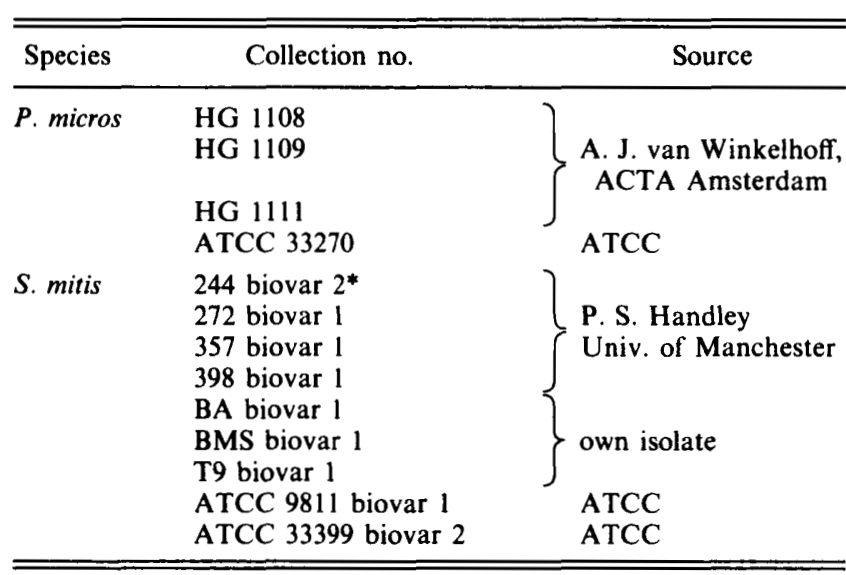

* Biovar assessed by checking for arginine hydrolysis (Kilian et al., 1989) as part of the API-20 STREP system.

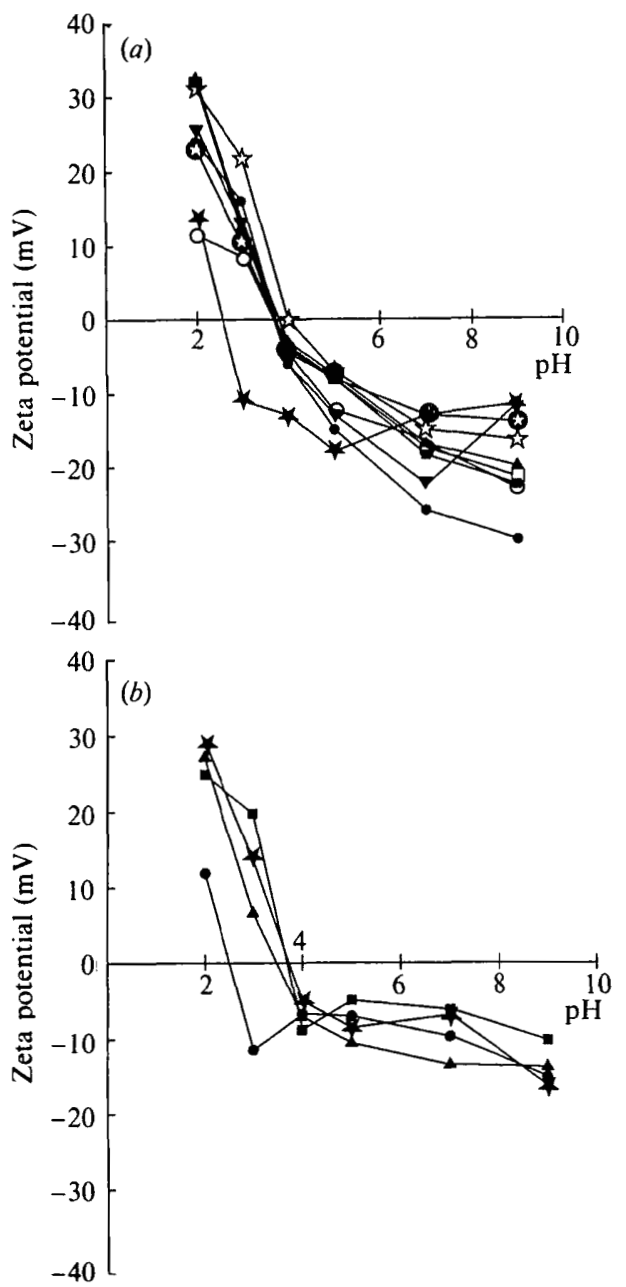

Fig. 1. Zeta potentials of $(a) S$. mitis and (b) P. micros as a function of $\mathrm{pH}$. Each curve represents the mean of two experiments with separate bacterial cultures, results of which coincided within $4 \mathrm{mV}$. S. mitis: $\nabla$, ATCC $9811 ; \star$, ATCC 33399; $\bullet$, BMS; 2 , 272; $\mathbf{\Delta}, 244 ; \square, 398 ; \mathbf{\square}$,

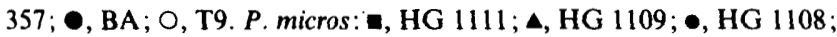
$\star$ ATCC 33270 . 
$\mathrm{X}$-ray production $(14 \mathrm{kV}, 20 \mathrm{~mA})$. After a scan of the overall spectrum, peaks were recorded in the following order: $C_{1 s}, O_{1 s}, N_{1 s}, P_{2 p}$, and $C_{1 s}$ again. The area under each peak after linear background subtraction was used for calculation of the peak intensities, yielding the elemental surface concentration ratios $\mathrm{O} / \mathrm{C}, \mathrm{N} / \mathrm{C}$, and $\mathrm{P} / \mathrm{C}$. The $\mathrm{C}_{1 \mathrm{~s}}$ peak was decomposed into three components, assuming a pure Gaussian shape and using a best-fit program. The components were set at $285.0 \mathrm{eV}$ (C$\mathrm{C}$ and $\mathrm{C}-\mathrm{H}$ bonds), $286.6 \mathrm{eV}$ (C-O and $\mathrm{C}-\mathrm{N}$ groups) and $288.4 \mathrm{eV}$ (HNC $=0$ groups) (Ratner \& McElroy, 1985).

Electron microscopy. Bacteria suspended in demineralized water were negatively-stained with $2 \%(\mathrm{w} / \mathrm{v})$ methylamine tungstate according to Hancock \& Poxton (1988). Briefly, a suspension of bacteria was applied to a carbon film-coated copper grid and the excess liquid removed. Stain was then applied for $30 \mathrm{~s}$, after which the excess was removed. Preparations were viewed with a Philips 201 transmission electron microscope operating at $80 \mathrm{kV}$.

\section{Results}

\section{Zeta potentials of S. mitis and P. micros}

Fig. 1 depicts the pH-dependence of the zeta potentials of the nine $S$. mitis and four $P$. micros strains. All strains displayed a $\mathrm{pH}$-dependence which is characteristic of mixed amino/carboxyl surfaces (James, 1982) with positive zeta potentials at low $\mathrm{pH}$ values and negative zeta potentials at $\mathrm{pH}$ values higher than 4 . Both genera showed a tendency to be highly positively charged at low $\mathrm{pH}$ values.

The isoelectric points (IEP; the point at which the zeta potential is zero) of three of the four $P$. micros and eight of the nine $S$. mitis strains were greater than 3.5 . At higher $\mathrm{pH}$ values, $S$. mitis strains displayed more rapidly increasing negative zeta potentials than did $P$. micros strains.

\section{Contact angles on $S$. mitis and P. micros}

Data obtained from contact angle measurements on lawns of the 13 strains are shown in Table 2. Wide variation in the liquid contact angles can be seen within as well as between the two genera. On average, however, $S$. mitis strains were more hydrophobic than $P$. micros strains.

Fig. 2 depicts the relationships between contact angles obtained with the two polar liquids (Fig. $2 a$ ) and with the

Table 2. Contact angles of different pure liquids on lawns of $P$. micros and $S$. mitis strains

Contact angles are in degrees. Data are mean values of four experiments performed on two separate bacterial cultures. Standard deviation $\leqslant 9^{\circ}$ unless otherwise indicated.

\begin{tabular}{lcccc}
\hline \hline \multicolumn{1}{c}{ Bacterium } & $\theta \mathrm{H}_{2} \mathrm{O}$ & $\theta$ formamide & $\theta$ diiodomethane & $\theta \alpha$-br \\
\hline P. micros & & & & \\
HG 1108 & $66^{3}$ & 69 & 51 & 34 \\
HG 1109 & 33 & 49 & 58 & 43 \\
HG 1111 & 58 & 70 & 55 & $34 \dagger$ \\
ATCC 33270 & 39 & 49 & 72 & 51 \\
S. mitis & & & & \\
244 & 60 & 38 & 47 & 30 \\
272 & 54 & 39 & 51 & 30 \\
357 & 53 & 31 & 42 & 33 \\
398 & 59 & 33 & 48 & 26 \\
BA & 103 & 55 & 49 & 35 \\
BMS & 100 & 43 & 50 & 34 \\
T9 & 91 & 47 & 55 & 36 \\
ATCC 9811 & 68 & 53 & 48 & 31 \\
ATCC 33399 & 56 & 40 & 45 & 31 \\
\hline \hline
\end{tabular}

* $\alpha$-br, alpha-bromonapthalene.

$\dagger \mathrm{SD}=17^{\circ}$.

Table 3. X-ray photoelectron spectroscopy of $S$. mitis and P. micros

Data are means of 2 determinations on separate bacterial cultures and were reproducible within $\pm 10 \%$.

\begin{tabular}{|c|c|c|c|c|c|c|}
\hline \multirow[b]{2}{*}{ Bacterium } & \multicolumn{3}{|c|}{ Surface concentration ratios } & \multicolumn{3}{|c|}{ Peak components of $C_{1 s}$ at } \\
\hline & $\mathrm{N} / \mathrm{C}$ & $\mathrm{O} / \mathrm{C}$ & $\mathrm{P} / \mathrm{C}$ & $285.0 \mathrm{eV}$ & $286.6 \mathrm{eV}$ & $288.4 \mathrm{eV}$ \\
\hline \multicolumn{7}{|l|}{ P. micros } \\
\hline HG 1108 & $0 \cdot 139$ & 0.306 & 0.003 & 0.49 & 0.36 & $0 \cdot 17$ \\
\hline HG 1109 & $0 \cdot 125$ & 0.277 & 0.003 & 0.58 & $0 \cdot 32$ & $0 \cdot 10$ \\
\hline HG 1111 & $0 \cdot 137$ & 0.295 & 0.004 & 0.61 & 0.24 & $0 \cdot 15$ \\
\hline ATCC 33270 & 0.074 & $0 \cdot 215$ & 0.014 & 0.74 & $0 \cdot 19$ & 0.08 \\
\hline \multicolumn{7}{|l|}{ S. mitis } \\
\hline 244 & 0.097 & 0.314 & 0.008 & 0.54 & $0 \cdot 32$ & $0 \cdot 14$ \\
\hline 272 & 0.131 & $0 \cdot 348$ & 0.008 & 0.51 & 0.35 & $0 \cdot 15$ \\
\hline 357 & 0.119 & 0.339 & 0.011 & 0.50 & 0.36 & $0 \cdot 14$ \\
\hline 398 & $0 \cdot 116$ & 0.261 & 0.008 & 0.57 & 0.29 & $0 \cdot 14$ \\
\hline BA & 0.129 & 0.326 & 0.007 & 0.60 & 0.28 & 0.13 \\
\hline BMS & $0 \cdot 124$ & 0.312 & 0.009 & 0.57 & 0.29 & $0 \cdot 14$ \\
\hline T9 & 0.125 & 0.259 & 0.006 & 0.63 & 0.25 & $0 \cdot 13$ \\
\hline ATCC 9811 & 0.110 & 0.303 & 0.008 & 0.60 & 0.28 & $0 \cdot 12$ \\
\hline ATCC 33399 & $0 \cdot 106$ & $0 \cdot 343$ & 0.008 & 0.58 & 0.31 & $0 \cdot 12$ \\
\hline
\end{tabular}



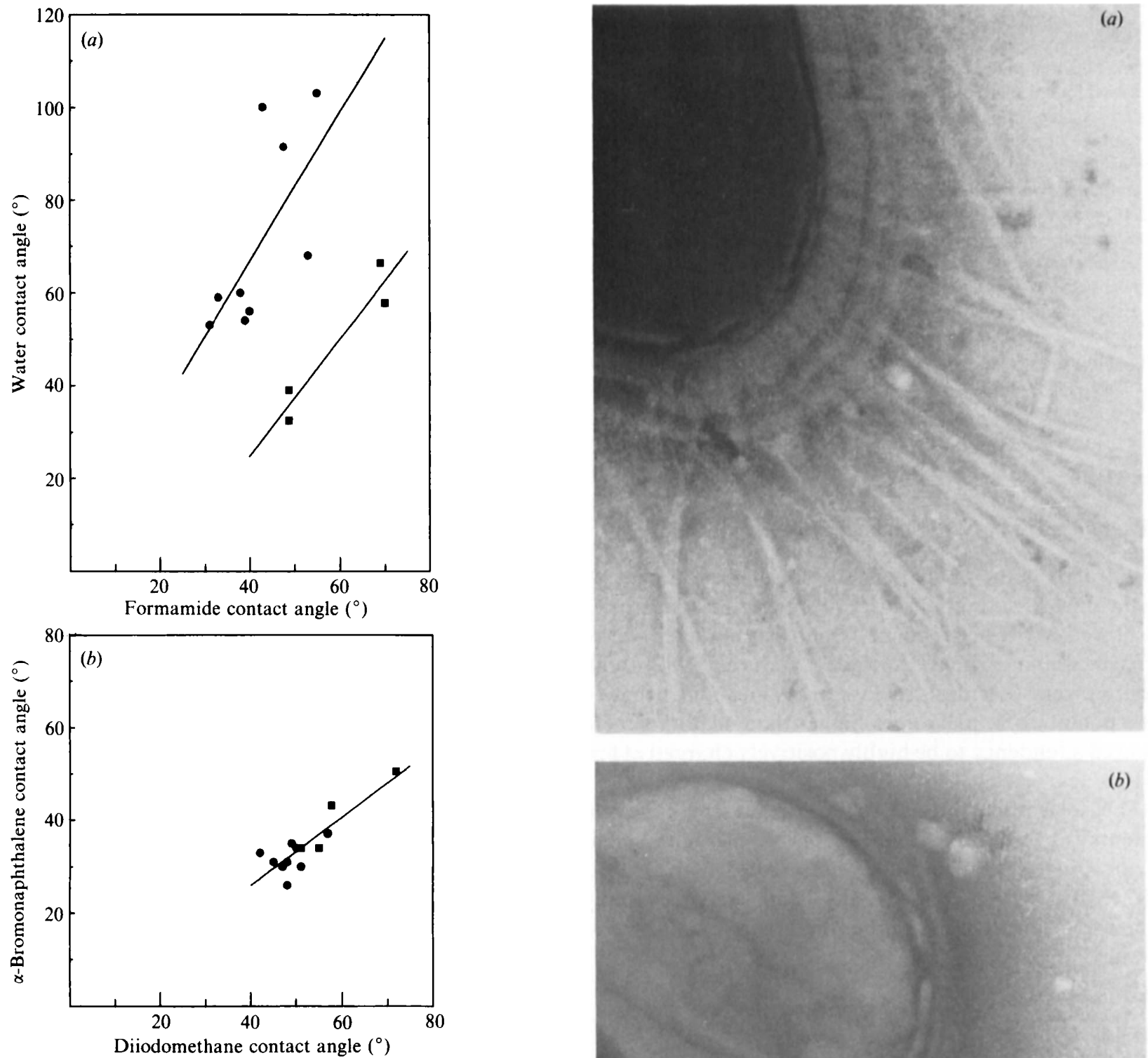

Fig. 2. Relationship between the contact angles of water and formamide $(a)$ and $\alpha$-bromonaphthalene and diiodomethane $(b)$ on lawns of $P$. micros $(\square)$ and $S$. mitis $(\bullet)$ strains.

two apolar liquids (Fig. 2b). All $S$. mitis and P. micros strains displayed the same relationship between $\alpha$ bromonaphthalene and diiodomethane contact angles. This was not the case with the two polar liquids. The four $P$. micros strains displayed a relationship between contact angles found with water and formamide which clearly differed from that of the $S$. mitis strains.

\section{Elemental surface composition}

Table 3 contains data representing elemental surface concentration ratios for the surfaces of $S$. mitis and

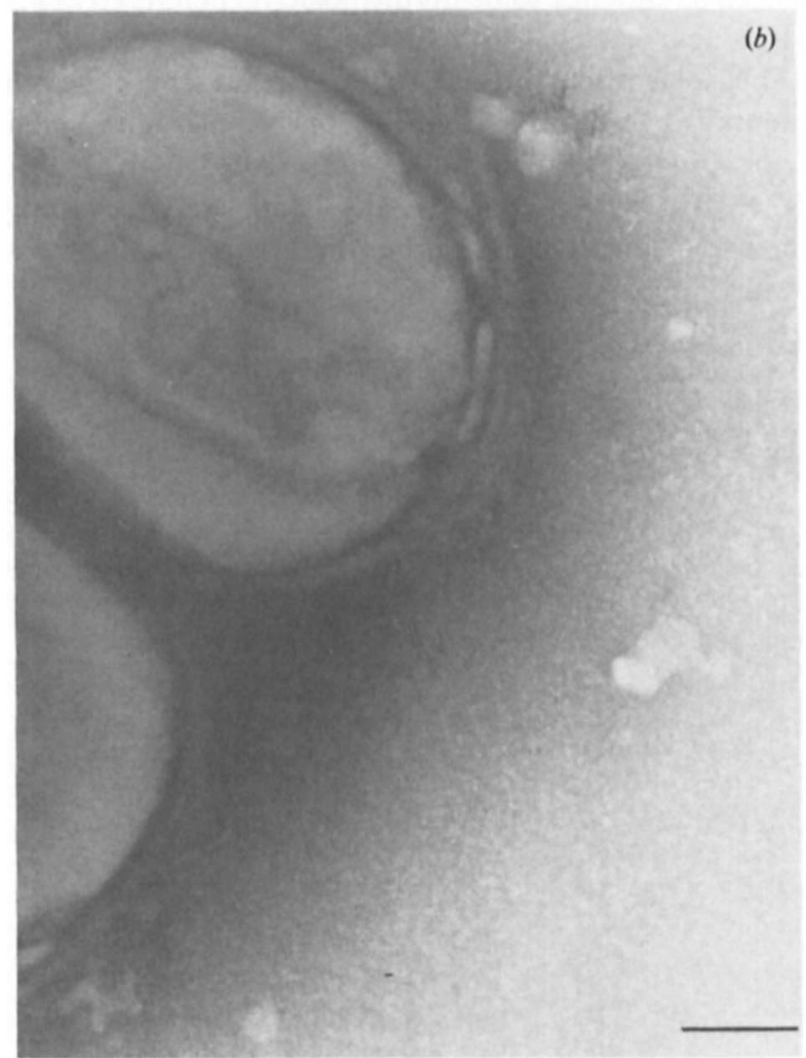

Fig. 3. Transmission electron microscopy of negatively-stained $S$. mitis $(a)$ and $P$. micros (b) cells. Stain is $2.0 \%(\mathrm{w} / \mathrm{v})$ methylamine tungstate Bar, $100 \mathrm{~nm}$. 

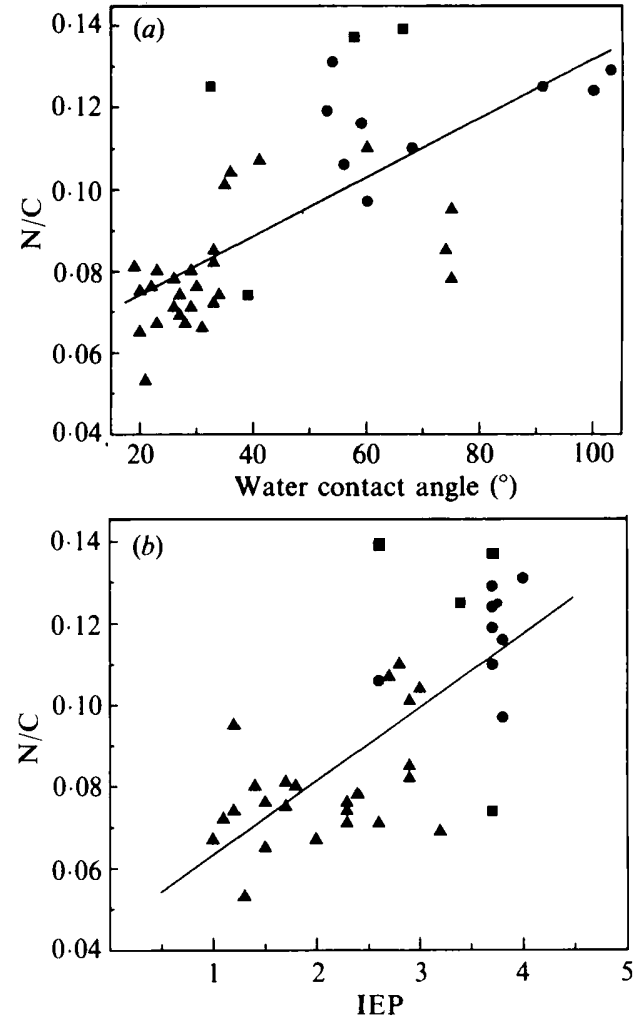

Fig. 4. N/C vs. water contact angle and isoelectric point for $S$. mitis $(\bullet), P$. micros $(\boldsymbol{\square})$, and other oral streptococci $(\boldsymbol{\Delta})$.

$P$. micros strains. Also listed are the fractions of components of which the $C_{1 s}$ peak was thought to be composed. Noteworthy are the relatively high values for $\mathrm{N} / \mathrm{C}$ for the three clinical isolates of $P$. micros and for the $S$. mitis strains. Also, in all 13 strains the component of the $\mathrm{C}_{1 \mathrm{~s}}$ peak set at $285.0 \mathrm{eV}$ (representing $\mathrm{C}-\mathrm{C}$ and $\mathrm{C}-\mathrm{H}$ bonds) was the most abundant of the three carboncontaining components.

\section{Electron microscopy}

Negative staining revealed long abundant fibrillar extensions on all $S$. mitis strains (Fig. $3 a$ ). No fibrils of any sort could be detected on any of the $P$. micros strains (Fig. 3b).

\section{Relationships among data obtained with different techniques}

Fig. 4 depicts the relationships between N/C and hydrophobicity (stated here as the water contact angle, Fig. $4 a$ ) as well as between N/C and IEP (Fig. $4 b$ ) for the four $P$. micros strains, the nine $S$. mitis strains, and a range of oral streptococci. The ratio $\mathrm{N} / \mathrm{C}$ is seen to correlate positively with IEP and with water contact angle. In addition, these graphs clearly illustrate the relatively high $\mathrm{N} / \mathrm{C}$ surface concentration ratio found for the $P$. micros and $S$. mitis strains.

\section{Discussion}

The two most notable features of the $S$. mitis and $P$. micros strains examined here are their exceptionally high $\mathrm{N} / \mathrm{C}$ surface concentration ratios and relatively high IEPs as compared to other oral streptococci which stimulated us to make a more detailed comparison of the surface properties of these two species. Table 4 summarizes these and other physico-chemical and compositional properties for the $S$. mitis and $P$. micros strains as well as for a group of 27 other oral streptococci (see Table footnote for list of strains). Values for the strains $P$. micros ATCC 33270 and S. mitis ATCC 33399 are excluded from the analysis since they were found to be atypical of their species (see below). In addition, previously unpublished elemental surface concentration ratios found by XPS are listed for freeze-dried preparations of $\alpha$-amylase and a glycoprotein isolated from human whole saliva and commercially obtained dextran and albumin. Comparison of the $\mathrm{N} / \mathrm{C}$ and $\mathrm{O} / \mathrm{C}$ values found for these macromolecules with those of the bacterial cell surfaces provide a clear indication that $P$. micros and $S$. mitis possess surfaces which are very rich in nitrogen and thus probably predominantly proteinaceous. XPS values for $P$. micros, and to a somewhat lesser extent for $S$. mitis, most closely approximate those of the salivary glycoprotein preparation. The surfaces of the group of other oral streptococci appeared to contain much less nitrogen and more oxygen than $P$. micros and $S$. mitis. Thus their surfaces are probably made out of oxygen rich polysaccharides (see dextran data) to a greater extent than those of $P$. micros and $S$. mitis. This conclusion is also supported by the percentage of carbon found at $286.6 \mathrm{eV}$ (Table 4). The value of 0.30 found for $P$. micros and $S$. mitis strains is comparable to the values found for all three of the macromolecules which consist either totally or in large part of protein ( $\alpha$-amylase, albumin and the salivary glycoprotein). In the case of both dextran and the group of oral streptococci, the $286.6 \mathrm{eV}$ fraction is much larger. The high isoelectric points found for the $S$. mitis and $P$. micros strains provide further evidence that high levels of surface protein are responsible for the high $\mathrm{N} / \mathrm{C}$ surface concentration ratios, since previous investigations (Amory et al., 1988; Van der Mei et al., 1988b) have found IEP to be closely correlated with amount of exposed protein.

Low $\mathrm{O} / \mathrm{C}$ surface concentration ratios were also found for both genera studied as compared to other oral 
Table 4. Physico-chemical and compositional data for oral bacteria, albumin, dextran and isolated freeze-dried salivary components

Isolation methods as in Pratt-Terpstra et al. (1991). P. micros differs significantly from $S$. mitis only in P/C, but 'other oral streptococci' differ significantly from $P$. micros and $S$. mitis in IEP, $\theta_{\mathrm{H}_{2} \mathrm{O}}, \mathrm{N} / \mathrm{C}, \mathrm{O} / \mathrm{C}$ and $\mathrm{C}_{1 \mathrm{~s}}$ at 285.0 and $286.6 \mathrm{eV}$ (Student's $t, P<0.01$ ).

\begin{tabular}{|c|c|c|c|c|c|c|c|c|}
\hline \multirow[b]{3}{*}{ Test subject } & \multirow[b]{3}{*}{ IEP } & \multirow[b]{3}{*}{$\theta_{\mathrm{H}_{2} \mathrm{O}}$} & \multicolumn{6}{|c|}{ XPS } \\
\hline & & & \multicolumn{3}{|c|}{ Surface concn. ratios } & \multicolumn{3}{|c|}{ Peak components of $C_{1 s}$ at } \\
\hline & & & $\mathrm{N} / \mathrm{C}$ & $\mathrm{O} / \mathrm{C}$ & $\mathrm{P} / \mathrm{C}$ & $285.0 \mathrm{eV}$ & $286 \cdot 6 \mathrm{eV}$ & $288.4 \mathrm{eV}$ \\
\hline $\begin{array}{l}\text { P. micros* } \\
\text { S. mitis } \dagger \\
\text { Other oral streptococci } \ddagger\end{array}$ & $\begin{array}{l}3.2 \pm 0.5 \\
3 \cdot 6 \pm 0.4 \\
2 \cdot 1 \pm 0.7\end{array}$ & $\begin{array}{l}52 \pm 14 \\
74 \pm 20 \\
34 \pm 16\end{array}$ & $\begin{array}{l}0.134 \pm 0.006 \\
0.119 \pm 0.010 \\
0.074 \pm 0.013\end{array}$ & $\begin{array}{l}0.293 \pm 0.012 \\
0.308 \pm 0.030 \\
0.427 \pm 0.042\end{array}$ & $\begin{array}{l}0.003 \pm 0.000 \\
0.008 \pm 0.001 \\
0.004 \pm 0.003\end{array}$ & $\begin{array}{l}0.57 \pm 0.05 \\
0.56 \pm 0.04 \\
0.45 \pm 0.07\end{array}$ & $\begin{array}{l}0 \cdot 30 \pm 0.04 \\
0 \cdot 30 \pm 0 \cdot 04 \\
0 \cdot 41 \pm 0 \cdot 05\end{array}$ & $\begin{array}{l}0 \cdot 14 \pm 0 \cdot 03 \\
0 \cdot 14 \pm 0 \cdot 01 \\
0 \cdot 14 \pm 0 \cdot 03\end{array}$ \\
\hline $\begin{array}{l}\text { Salivary } x \text {-amylase } \\
\text { Albumin§ } \\
\text { Salivary glycoprotein } \\
\text { Dextran\| }\end{array}$ & $\begin{array}{l}- \\
- \\
- \\
-\end{array}$ & $\begin{array}{l}- \\
- \\
- \\
-\end{array}$ & $\begin{array}{c}0 \cdot 221 \\
0 \cdot 240 \\
0 \cdot 182 \\
\text { ND }\end{array}$ & $\begin{array}{l}0 \cdot 382 \\
0 \cdot 292 \\
0 \cdot 432 \\
0 \cdot 712\end{array}$ & $\begin{array}{l}0.008 \\
0.001 \\
0.003 \\
\text { ND }\end{array}$ & $\begin{array}{l}0.47 \\
0.50 \\
0.52 \\
0 \cdot 20\end{array}$ & $\begin{array}{l}0 \cdot 32 \\
0 \cdot 29 \\
0 \cdot 32 \\
0 \cdot 69\end{array}$ & $\begin{array}{l}0 \cdot 21 \\
0 \cdot 21 \\
0 \cdot 16 \\
0 \cdot 12\end{array}$ \\
\hline
\end{tabular}

ND, not detected.

* Mean values for $P$. micros strains HG 1108, HG 1109, HG 1111.

† Mean values for $S$. mitis strains 244, 272, 357, 398, BA, BMS, T9 and ATCC 9811.

¥ Mean values for 27 oral streptococcal strains: $S$. sobrinus strains HG 970, HG 1025 and HG 977; S. cricetus AHT, E49 and H56; S. rattus BHT, BHT $_{\mathrm{sm}}$, ATCC 19645 and FA1; S. mutans NS, HG 982, HG 983, HG 1003, HG 979 and HG 985; S. salivarius HB, HBC12, HBV 5, HB 7 and HBV 51 ; $S$. crista (previously $S$. sanguis) CR 311, CR $311 \mathrm{~V}_{1}, \mathrm{CR} 311 \mathrm{~V}_{2}$ and CR $311 \mathrm{~V}_{3} ; S$. sanguis PSH and CH3 (Van der Mei et al., 1988 a; Van der Mei et al., 1991 ; Busscher et al., 1991).

$\S$ Albumin Fraction V, Sigma.

|l Dextran 500; molecular mass 500-700 kDa (serva).

streptococci. This observation corresponds with their elevated IEP and suggests that the two bacteria possess little or no extracellular capsular-type material, which is often rich in negative charges (especially phosphate and carboxyl groups) and can mask underlying wall or fibril proteins.

Protein may not be the only abundant macromolecule on the surface of $P$. micros and $S$. mitis strains. Decomposition of the carbon peak obtained from XPS revealed that the first carbon component situated at $285.0 \mathrm{eV}$, and attributed to the position of carbon involved in hydrocarbon bonds, is much more dominant in $S$. mitis and P. micros strains than in the other streptococci studied (Tables 3 and 4). This suggests that lipid, which is readily found in Gram-positive organisms in the form of lipoteichoic acids and other amphiphilic wall polymers (Wicken \& Knox, 1983), may be present either in a bound form or as a secreted polymer at the cell surface. It could then be expected to have a variable influence on physico-chemical surface properties depending on its orientation.

Although there is wide variation in the wettability of the surfaces of all the strains studied here, the overall high water contact angles as compared to those for the other streptococcal strains is consistent with a comparatively large amount of surface protein. Since no fibrillar appendages were found on $P$. micros strains, it appears that the protein is integral to the cell envelope itself, perhaps in the form of cell wall protein or protein adsorbed from the growth medium. No evidence could be found for the presence of a surface array or S-layer structure which could account for high protein levels. The lower degree of hydrophobicity compared to $S$. mitis strains, in combination with approximately equivalent IEPs and a N/C surface concentration ratio that is even higher than that for $S$. mitis, suggests that protein may have been masked in the semi-hydrated preparations used in contact angle measurements but not under the fully hydrated zeta potential conditions. Such a possible masking effect would be least likely to influence the XPS measurements because XPS probes more deeply (approximately $5 \mathrm{~nm}$ ) than do the other techniques (zeta potentials probe at the plane of shear between the bacterial cell and the fluid (James, 1982); contact angles measure the outermost $0 \cdot 4-0.5 \mathrm{~nm}$ of the semi-hydrated bacterial pellet (Bain \& Whitesides, 1988)).

The relationships between the contact angles of two polar liquids for $P$. micros is not the same as that for the $S$. mitis strains (Fig. 2) and may be further evidence for fundamental differences in the type and/or structural arrangement of exposed surface protein present in the two genera.

It should be noted that two strains considered to be type strains of their species differ in significant ways 
from the majority of clinical isolates of these strains. $S$. mitis ATCC 33399 had a lower IEP than the other eight S. mitis bacteria (Fig. 1, Table 2). Also, the three clinical isolates of $P$. micros displayed $\mathrm{N} / \mathrm{C}$ surface concentration ratios almost twice as high as ATCC strain 33270 and $\mathrm{P} / \mathrm{C}$ surface concentration ratios that were a fraction of that found for the type strain (Table 3 ). This is an important indication that while type strains may be biochemically representative of their species, cell surface properties, which are characteristically labile, are often grossly altered.

It is also worth mentioning that the three $S$. mitis strains with extremely high water contact angles (BA, BMS, and T9, see Table 2) were all isolated from buccal mucosa. S. mitis ATCC 33399, on the other hand, was originally isolated from the dentition and displays a lower water contact angle (the origin of the other $S$. mitis strains is not known). It is interesting to speculate that even though all $S$. mitis strains possess abundant surface fibrils, the composition of these fibrils and other surface components may differ in such a way as to correlate with their original intra oral isolation site. Other authors have also observed that strains isolated from oral soft tissue may be more hydrophobic than strains isolated from dental hard tissues (Beighton, 1984). Alternatively, it might be anticipated that the various hydrophobicities observed for the $S$. mitis strains correspond with their biovar, as recently described for Fusobacterium necrophorum (Shinjo et al., 1987). Comparison of Table 1 with the data on water contact angles of the $S$. mitis strains presented in Table 2 shows that this observation does not hold for the present collection of $S$. mitis strains and hydrophobicity as assessed by water contact angles.

Originally, horse serum was added to peptone yeast extract medium for the growth of $P$. micros strains to better mimic the situation in the periodontal pocket, the predominant niche of this organism. Later on, addition of serum to peptone yeast extract medium turned out to be essential for growth of $P$. micros cells in this medium. Some $P$. micros strains (HG 1109 and ATCC 33270), however, have also been grown in Schaedler's broth with and without serum added. The zeta potentials of these two $P$. micros strains grown in Schaedler's broth with serum added were not greatly different than those of cells grown in peptone yeast extract medium with serum added. However, deletion of serum from Schaedler's broth resulted in slightly more hydrophobic cells with a lower $\mathrm{N} / \mathrm{C}$ surface concentration ratio. This suggests that $P$. micros cells adventitiously adsorb serum proteins, consistent with the lack of microscopically visible surface structures on these strains. For supragingival oral streptococci, such an adventitious adsorption of proteins upon bathing cells in saliva has not been observed, as their N/C surface concentration ratios by XPS increased only slightly upon adsorption of salivary components (Van der Mei et al., 1989b).

In summary, the surfaces of $P$. micros and $S$. mitis strains possessed much higher IEPs and contained higher $\mathrm{N} / \mathrm{C}$ and lower $\mathrm{O} / \mathrm{C}$ surface concentration ratios than other oral streptococci studied. The data obtained with various techniques correlated with each other and suggest that the surfaces of both species are dominated by protein. $S$. mitis strains possess surface fibrils which are the probable location of the abundant surface protein. $P$. micros strains were found to be devoid of surface appendages and are therefore most likely to be rich in cell wall protein, either intrinsic to the cells or adsorbed from their growth environment. The surfaces of type strains of both species were found not to be representative of the majority of strains.

The authors wish to thank Ietse Stokroos for his assistance with electron microscopy and Marjon Schakenraad for preparation of the manuscript.

\section{References}

Abramson, H. A., Moyer, L. S. \& Gorin, M. H. (1942). The Electrophoresis of Proteins and the Chemistry of Cell Surfaces. New York: Reinholz.

Amory, D. E., Genet, M. J. \& Rouxhet, P. G. (1988). Application of XPS to the surface analysis of yeast cells. Surface and Interface Analysis, 11, 478-486.

Bain, C. D. \& Whitesides, G. M. (1988). Molecular-level control over surface order in self-assembled monolayer films of thiols on gold. Science, 240, 62-63.

Beighton, D. (1984). The influence of saliva on the hydrophobic surface properties of bacteria isolated from oral sites of macaque monkeys. FEMS Microbiology Letters 21, 239-242.

Bourgault, A. M., Rosenblatt, J. E. \& Fitzgerald, R. H. (1980). Peptococcus magnus: a significant human pathogen. Annals of Internal Medicine 93, 244-248.

Busscher, H. J., Weerkamp, A. H., van der Mei, H. C., van Pelt, A. W. J., DE Jong, H. P. \& ARends, J. (1984). Measurement of the surface free energy of bacterial cell surfaces and its relevance for adhesion. Applied and Environmental Microbiology 48, 980-983.

BusSChER, H. J. \& WeERKamp, A. H. (1987). Specific and non-specific interactions in bacterial adhesion to solid substrata. FEMS Microbiology Reviews 46, 165-173.

Busscher, H. J., Handley, P. S., Rouxhet, P. G., Hesketh, L. M. \& VAN DER MEI, H. C. (1991). The relationship between structural and physicochemical surface properties of tufted Streptococcus sanguis strains. In Microbial Cell Surface Analysis - Structural and Physicochemical methods, pp. 317-338. Edited by N. Mozes, P. S. Handley, H. J. Busscher \& P. G. Rouxhet. New York: VCH Publishers.

Hancock, I. \& Poxton, I. (1988). Bacterial Cell Surface Technique, pp. 281-286. Edited by I. Hancock \& I. Poxton. Chichester: Wiley.

HARDIE, I. M. \& MARSH, P. D. (1978). Streptococci and the human oral flora. In Streptococci, p. 162. Edited by F. A. Skinner \& L. B. Quesnel. London: Academic Press.

HofsTAD, T. (1985). The classification and identification of the anaerobic Gram-positive cocci. Scandinavian Journal of Infectious Diseases Supplement 46, 14-17.

JAMES, A. M. (1982). The electrical properties and topochemistry of bacterial cells. Advances in Colloid and Interface Science 15, 171-221.

Kilian, M. Mikkelsen, L. \& HenRichsen, J. (1989). Taxonomic study of viridans streptococci: description of Streptococcus gordonii sp. nov. and emended descriptions of Streptococcus sanguis (White and 
Niven 1946), Streptococcus oralis (Bridge and Sneath 1982), and Streptococcus mitis (Andrews and Horder 1906). International Journal of Systematic Bacteriology 4, 471-484.

MARSh, P. D. \& MARTIN, M. V. (1980). Aspects of Microbiology series. In Oral Biology, 2nd. edition, p. 14. Washington DC: American Society for Microbiology.

Millard, M. M., ScherRer, R. \& Thomas, R. S. (1976). Surface analysis and depth profile composition of bacterial cells by X-ray photoelectron spectroscopy and oxygen plasma etching. Biochemical and Biophysical Research Communications 72, 1209-1217.

Moore, W. E. C., Holdeman, L. V., Smibert, R. M., Hash, D. E. \& RANNEY R. R. (1982). Bacteriology of severe periodontitis in young adult humans. Infection and Immunity 38, 1137-1148.

Mozes, N., Amory, D. E., Leonard, A. J. \& Rouxhet, P. G. (1989). Surface properties of microbial cells and their role in adhesion and flocculation. Colloids and Surfaces 42, 313-329.

Olsson, J., Glantz, P. O. \& Krasse, B. (1976). Electrophoretic mobility of oral streptococci. Archives of Oral Biology 21, 605-609.

Pratt-Terpstra, I. H., Mulder, J., Weerkamp, A. H., Feijen, J. \& Busscher, H. J. (1991). Secretory IgA adsorption and oral streptococcal adhesion to human enamel and artificial solid substrata with various surface free energies. Journal of Biomaterials Science Polymer Edition 2, 239-253.

RATNER, B. D. \& MCELROY, B. J. (1985). Electron spectroscopy for chemical analysis: applications in the biomedical sciences. In Spectroscopy in the Biomedical Sciences, pp. 107-140. Edited by R. M. Gendrau. CRC Press.

Rogosa, M. (1971). Peptococcaceae, a new family to include the Grampositive anaerobic cocci of the genera. Peptococcus, Peptostreptococcus, and Ruminococcus. International Journal of Systematic Bacteriology 21, 234-237.

Shinjo, T., HazU, H. \& Kiyoyama, H. (1987). Hydrophobicity of Fusobacterium necrophorum biovars A and B. FEMS Microbiology Letters 48, 243-247.

Silva-Filho, F. C. E., Saraiva, E. M. B., Santos, M. A. V. \& DE SouZA, W. (1990). The surface free energy of Leishmania mexicana amazonensis. Cell Biophysics 17, 137-151.

SLOTS, J. (1979). Subgingival microflora and periodontal disease. Journal of Clinical Periodontology 6, 351-382.
SoCransKy, S. S. (1970). Relationship of bacteria to the etiology of periodontal disease. Journal of Dental Research 49, 203-222.

TaM, Y-C., Noble, P. B. \& Chan, E. C. S. (1987). Effects of extracellular products of a presumed gingival pathogen, the bacterium Peptostreptococcus $84 \mathrm{H} 14 \mathrm{~S}$, on cultured human fibroblasts and Hela cells. Archives of Oral Biology 4, 303-305.

Ter Steeg, P. F., van der Hoeven, J. S., De Jong, M. H., van Munster, P. J. J. \& JANSEN, M. J. H. (1987). Enrichment of subgingival microflora on human serum leading to accumulation of Bacteroides species, Peptostreptococci and Fusobacteria. Antonie van Leeuwenhoek 53, 261-271.

VAN Der Mei, H. C., Leonard, A. J., Weerkamp, A. H., Rouxhet, P. G. \& BUSSCHER, H. J. (1988a). Surface properties of Streptococcus salivarius HB and non-fibrillar mutants : zeta potential and elemental composition using X-ray photoelectron-spectroscopy. Journal of Bacteriology 170, 2462-2466.

Van der Mei, H. C., Leonard, A. J., Weerkamp, A. H., RouXhet, P. G. \& Busscher, H. J. (1988b). Properties of oral streptococci relevant for adherence: zeta potential, surface free energy and elemental composition. Colloids and Surfaces 32, 297-305.

VAN Der Mei, H. C., Brokke, P., Dankert, J., FeiJen, J., Rouxhet, P. G. \& BussCher, H. J. (1989a). Physicochemical surface properties of nonencapsulated and encapsulated coagulase-negative staphylococci. Applied and Environmental Microbiology 55, 2806-2814.

V AN DER Mei, H. C., Genet, M. J., Weerkamp, A. H., RouXhet, P. G. \& BUssCher, H. J. (1989b). A comparison between the elemental surface compositions and electrokinetic properties of oral streptococci with and without adsorbed salivary constituents. Archives of Oral Biology 34, 889-894.

VAN Der Mei, H. C., De Soet, J. J., De Graaff, J., Rouxhet, P. G. \& BUSSCHER, H. J. (1991). Comparison of the physicochemical surface properties of Streptococcus rattus with those of other mutans streptococcal species. Caries Research 25, 415-423.

Van LoOsDrecht, M. C. M., Lyklema, J., Norde, W., SchraA, G. \& ZEHNDER, A. J. B. (1987). Electrophoretic mobility and hydrophobicity as a measure to predict the initial steps of bacterial adhesion. Applied and Environmental Microbiology 53, 1898-1901.

WICKEN, A. J. \& KNOX, K. W. (1983). Cell surface amphiphiles of Gram-positive bacteria. Toxicon, suppl. 3, 501-507. 